\title{
Bibliografía sobre Derecho Administrativo del Turismo ${ }^{1}$
}

\author{
María Matilde Ceballos Martín \\ Raúl Pérez Guerra
}

Profs. Titulares de Derecho Administrativo

Universidad de Almería

Profs. Tutores-Consultores de la Universidad Oberta de Cataluña Asociación Española de Expertos Científicos en Turismo -AECIT-

\section{DERECHO ADMINISTRATIVO DEL TURISMO DE ESPANAA}

\footnotetext{
${ }^{1}$ Trabajo realizado bajo el marco del Curso de Doctorado "Hacia la configuración del Derecho del Turismo", impartido en la Universidad de Almería.

A continuación se incorpora el índice de este repertorio bibliográfico que hemos sistematizado según el siguiente orden:

I. Derecho Administrativo del Turismo de España.

1. Legislación.

1.1. Ediciones oficiales.

1.2. Recopilaciones privadas.

2. Jurisprudencia.

2.1. Recopilaciones privadas.

3. Revistas especializadas.

3.1. Enumeración.

3.2. Artículos.

4. Repertorios bibliográficos.

5. Obras Generales de Derecho Administrativo.

6. Comentarios a la Constitución Española.

7. Comentarios a los Estatutos de Autonomía.

8. Comentarios a la Ley Reguladora de las Bases de Régimen Local.

9. Obras de Derecho Administrativo del Turismo.

10. Libros Homenaje.

11. Actas de Congresos, Seminarios y Jornadas de Estudio.

12. Enciclopedias y Diccionarios.

II. Derecho Administrativo del Turismo Italo-Francés.

1. Bibliografía italiana y francesa seleccionada.

1.1. Italiana.

1.2. Francesa.
} 


\section{Legislación.}

\subsection{Ediciones oficiales.}

CONSEJERÍA DE TURISMO, COMERCIO Y DEPORTE DE LA JUNTA DE ANDALUCÍA, Nueva Legislación Turística de Andalucía, $2^{\underline{a}}$ ed., 2 vol., Junta de Andalucía, Consejería de Turismo, Comercio y Deporte, Sevilla, 2004.

CONSEJERÍA DE CULTURA, EDUCACIÓN Y TURISMO. DIRECCIÓN GENERAL DE TURISMO, Legislación Turística de la Región de Murcia, Dirección General de Turismo, Murcia, 1991.

J. A. CRUZ MÉNDEZ, Ordenación Turística de Andalucía, ed. Turismo Andaluz, Sevilla, 1993.

MINISTERIO DE TRANSPORTES, TURISMO Y COMUNICACIONES, Legislación de las Comunidades Autónomas sobre turismo, 5 vol., 1988, Legislación estatal sobre turismo, 2 vol., 1986.

SECRETARÍA DE ESTADO DE TURISMO, Normas Técnicas y de Planeamiento para Urbanizaciones Turísticas, Madrid, 1977.

\subsection{Recopilaciones privadas.}

A. ASPIAZU MONTEYS, Código completo de Turismo, ed. De Vecchi, Barcelona, 1987.

F. BAYÓN MARINE, Legislación Turística Española, ed. Cívitas, Madrid, 1987.

Competencias en materia de Turismo, Ordenación del Turismo, Régimen Económico y Fiscal, Régimen Laboral, Ordenación de Alojamientos y Restauración I, Ordenación de Alojamientos y Restauración II, Legislación de Agencias de Viajes, ed. Síntesis, Biblioteca Jurídica de Turismo, Madrid, 1992.

A. BLASCO ESTÉVE y F. SEGURA FUSTER, Legislación Turística Estatal y Balear, Universidad de las Islas Baleares, IBATUR, Palma, 1994.

R. CABALLERO SÁNCHEZ, Código sobre Legislación Turística, ed. Mac. Graw Hill, Madrid, 2000. 
J. FERNÁNDEZ ÁLVAREZ, Legislación Turística Española, 2 vol., Servicio de Publicaciones del Ministerio de Información y Turismo, Imnasa, Madrid, 1966.

R. GARCÍA MACHO (y otros), Normativa Turística, ed. Tirant lo Blanch, Valencia, 2004.

O. MARLASCA MARTÍNEZ, Legislación Turística, 2 ed., ed. Universidad de Deusto, Bilbao, 1994.

E. MARTÍNEZ DE SALINAS Y MENDOZA, Textos Legales: Turismo, Servicio de Publicaciones del Ministerio de Información y Turismo, Imprenta del BOE, Madrid, 1962.

J. ORTIZ DE MENDÍVIL, Hostelería: compendio de legislación vigente, con comentarios, concordancias, notas, jurisprudencia y formularios, Nuevas Gráficas, Madrid, 1966.

R. PÉREZ GUERRA y M. M. CEBALLOS MARTÍN, "Relación de disposiciones de Derecho Turístico Español dictadas a lo largo del siglo XX (ordenadas y sistematizadas por Administraciones y materias)", Documentación Administrativa, 259-260, enero-agosto, (2001), pp. 371 a 589.

"La legislación turística en 1996”, en La actividad turística española en 1996, ed. Asociación Española de Expertos Científicos en Turismo y Grupo Nexo, Madrid, 1997, pp. 569 a 579.

"La legislación turística en 1997", en La actividad turística española en 1997, ed. Asociación Española de Expertos Científicos en Turismo y Universidad de Almería, Madrid, 1998, pp. 601 a 617.

"La legislación turística en 1998", en La actividad turística española en 1998, ed. Asociación Española de Expertos Científicos en Turismo y Universidad de Almería, Madrid, 1999, pp. 691 a 712.

“La legislación turística en 1999”, en La actividad turística española en 1999, ed. Asociación Española de Expertos Científicos en Turismo, Madrid, 2000, pp. 635 a 654 .

"La legislación turística en 2000", en La actividad turística española en 2000, ed. Asociación Española de Expertos Científicos en Turismo, Madrid, 2001, pp. 647 a 666. 
“La legislación turística en 2001”, en La actividad turística española en 2001, ed. Asociación Española de Expertos Científicos en Turismo, Madrid, 2002, pp. 721 a 735 .

"La legislación turística en 2002", en La actividad turística española en 2002, ed. Asociación Española de Expertos Científicos en Turismo, Madrid, 2003, pp. 560 a 570.

"La legislación turística en 2003", en La actividad turística española en 2003, ed. Asociación Española de Expertos Científicos en Turismo, Madrid, 2004.

I. QUINTANA CARLO y O. SÁNCHEZ GIL, Legislación Turística Básica, ed. Tecnos, Madrid, 1997.

E. ROCA ROCA, M. M. CEBALLOS MARTÍN y R. PÉREZ GUERRA, Código de Turismo, $1^{a}$ ed., ed. Aranzadi, Elcano, 2001.

Código de Turismo, $2^{\mathrm{a}}$ ed., (declarado "Libro de interés Turístico Nacional"), ed. Thomson-Aranzadi, Elcano, 2004.

AA.VV, Normativa turística gallega, Servicio de Publicaciones de la Universidad de La Coruña, 2002.

\section{Jurisprudencia.}

\subsection{Recopilaciones privadas.}

E. ROCA ROCA, M. M. CEBALlOS MARTÍN y R. PÉREZ GUERRA, Código de Turismo, $1^{\underline{a}}$ ed., ed. Aranzadi, Elcano, 2001 (Parte Cuarta, titulada "Índice analítico de Jurisprudencia en materia de turismo”, pp. 731 a 751).

Código de Turismo, 2ae ed., ed. Thomson-Aranzadi, Elcano, 2004 (Parte Cuarta, titulada "Índice analítico de Jurisprudencia en materia de turismo", pp. 1011 a 1039).

AA.VV, Jurisprudencia de Hostelería IH, (fundamentalmente laboral), 2 vol., Ediciones Profesionales y Empresariales, S.A., Madrid, 1994.

AA.VV, Normativa turística gallega, Servicio de Publicaciones de la Universidad de La Coruña, 2002 (incluye jurisprudencia de los órganos jurisdiccionales gallegos de lo contencioso-administrativo). 


\section{Revistas especializadas.}

\subsection{Enumeración.}

Acta Turística, (Universidad de Zagreb, Croacia, desde 1992).

Annals of Tourism Research (Universidad de Wisconsin-Stout, Menomonie, Pergamon, USA, desde 1974)

Annals of Tourism Research en español (Universidad de las Islas Baleares, Palma de mallorca, desde 1999).

Aportes y Transferencias: tiempo libre, turismo y recreación (Universidad Nacional del Mar del Plata, Argentina, desde 1997).

Cuadernos de Turismo (Universidad de Murcia, desde 1998).

Estudios Turísticos (Instituto de Estudios Turísticos, desde 1963).

The journal of Torism Studies (Universidad de James Cook del Norte de Queensland, Australia, desde 1990).

Journal of Travel Research (Universidad de Colorado, USA, desde 1973).

Loisir et Societe, Society and Leisure (Universidad de Quebec, Canadá, desde 1979).

Papers de Turisme (Agencia Valenciana del Turismo, desde 1989).

Rassegna di Studi Turistici (Asociación Nacional Italiana de Expertos Científicos en Turismo, Roma, desde 1964).

Teoros: revue de recherche en tourisme (Universidad de Quebec y Montreal, Canadá, desde 1982).

Tourism and Hospitality Research: the Surrey quarterly review (Universidad de Surrey, Londres, desde 1999).

Tourism Review, Revue de Tourisme, Zeitschriff fur Fremdenverkehr (Asociación Internacional de Expertos Científicos en Turismo, St. Gallen, Suiza, desde 1954). 
Turismo en Analise (Universidad de Sao Paulo, Brasil, desde 1992).

World Travel, Tourisme Mondial (Organización Mundial del Turismo, Madrid, desde 1963).

\subsection{Artículos.}

J. de ARESPACOCHAGA FELIPE, "El Estado y el sector privado en el desarrollo turístico", RET, 4, (1964).

"La industria turística y la especulación del suelo", RET, núm. 8, (1965).

"La especulación del suelo en las zonas turísticas", Economía Financiera Española, 13 y 14, (1966).

R. ARNANZ DELGADO, "El turismo y los modos de actuación urbanísticos", Revista de Derecho Administrativo y Fiscal, 17 y 18, (1967).

L. ARREGUI y M. MIRÓ, "Los planes de extensión turístico-residencial en el Área Metropolitana de Madrid", RDU, 2, (1971).

J. I. de ARRILLAGA, "El control de la actividad de las agencias de viajes por la Administración Pública”, RET, 2, (1974).

J. M. ASPAS ASPAS, "Régimen Jurídico de los deportes de aventura. Consideraciones sobre el turismo activo", RArAP, Monográfico, (1999).

D. AZNAR JORDÁN, "Masas forestales, turismo y medio ambiente, breve análisis sobre el uso recreativo de los montes", RArAP, Monográfico, (1999).

I. BALLESTEROS ROS, "El turismo y su repercusión en la vida local", REVL,138, (1964).

"Los alojamientos extrahoteleros en España”, REVL,159, (1968).

J. BARCELÓ PÉREZ, "El turismo, preocupación necesaria y preferente para algunos ayuntamientos", El Alcalde, 17, (1968).

"Necesidades de la labor urbanizadora en una localidad turística", Municipalía, 187, (1969). 
R. BARRIL DOSSET, "Las oficinas municipales de Turismo en España”, Boletín de Información de la Vida Local, 29, (1970).

M. P. BENSUSAN MARTÍN, "Turismo y Patrimonio Cultural”, DA, Monográfica, 259-260, (2001).

J. BERMEJO VERA, “Administración Pública y Turismo”, REALA, 223, (1984).

"El deporte como recurso turístico", RArAP, Monográfico, (1999).

“Régimen Jurídico de los Municipios Turísticos”, DA, 259-260, (2001).

D. BLANQUER CRIADO, "Régimen Jurídico del Turismo Rural”, RArAP, Monográfico, 1999.

“¿Ordenación o desordenación del turismo?”, DA, 259-260, (2001).

F. J. BLANCO HERRAZ, "Fundamentos de la Política Comunitaria y Española en materia de Turismo Rural", RET, 131, (1996).

"Alternativas legislativas para la planificación territorial del turismo en España”, RArAP, Monográfico, (1999).

"Nuevas respuestas legislativas para la planificación territorial del turismo en España”, Revista Internacional Papers de Turisme, 27, (2000).

J. BONET CORREA, "El Ordenamiento Turístico Español”, RET, 12, (1966).

O. BOUAZZA ARIÑO, "Protección del medio ambiente, fiscalidad ambiental y turismo", REDA, 113, (2002).

R. CABALLERO SÁNCHEZ, "La normativa autonómica sobre disciplina turística y la innecesaria proliferación de procedimientos sancionadores en materia de turismo", $D A, 259-260$, (2001).

J. CALLIZO y A. LACOSTA, "Un estudio tipológico de los recursos turísticos", RArAP, Monográfico, (1999).

A. CARCELLER FERNÁNDEZ, "El Plan de Ordenación Urbana de los Centros de Interés Turístico Nacional”, $R D U$, 28, (1972). 
A. M. CARdona Álvarez, R. PÉREZ GUERRA y M. ${ }^{\text {a }}$ M. CEBAllos MARTÍN, "Reflexiones sobre el turismo y el empleo en España: el paro, las políticas de empleo y el papel del turismo en los procesos de creación de empleo", Revista Internacional Papers de Turisme, 28, (2000).

M. M. CEBALLOS MARTÍN, "Aspectos histórico-jurídicos de la entidad estatal empresarial Paradores de Turismo", DA, 259-260, (2001).

M. M. CEBALLOS MARTÍN y R. PÉREZ GUERRA, "Reflexiones sobre el Régimen Jurídico-Administrativo de las competencias en materia de turismo y de otros títulos que pueden incidir sobre el mismo", Revista Internacional Papers de Turisme, 19, (1995).

"Turismo y Derecho: subvenciones turísticas", Revista Internacional Papers de Turisme, 28, (2000).

"Reflexiones sobre el contrato turístico de alojamiento", Revista Internacional Papers de Turisme, 30, (2001).

M. CORCHERO PÉREZ y L. SANDÍN MORA, "Régimen jurídico-administrativo de la empresa turística. Especial referencia a la Comunidad Autónoma de Extremadura", Actualidad Administrativa, 24, (2002).

M. CORCHERO PÉREZ y L. SANDÍN MORA, "Régimen jurídico-administrativo de la empresa turística. Especial referencia a la Comunidad Autónoma de Extremadura", Actualidad Administrativa, 47-48, (2002).

L. CORNO CAPARRÓS, "El Estatuto Legal del Municipio Turístico: apuntes para una propuesta", REDA, 42, (1984).

G. CORTIÑAS BRAVO, "La especulación del suelo en las zonas turísticas", RET, 13, (1967).

J. M. de la CUÉTARA MARTÍNEZ, "Ideas para la reforma del Ordenamiento Turístico de Canarias", RCAP, 11, 12 y 13, (1991).

R. ENTRENA CUESTA, "Dictamen acerca de la aplicación de los artículos 32 y 42 de la Ley del Suelo en la tramitación de los Planes de Ordenación Urbana de Centros de Interés Turístico Nacional”, RDU, 13, (1969). 
"Dictamen acerca del alcance de los artículos 11 de la Ley de 28 de diciembre de 1963 y 43 de su Reglamento, en cuanto prescriben la adecuación de los Planes de Ordenación Urbana en los Centros de Interés Turístico Nacional a los planes urbanísticos ya aprobados que afecten al sector en que se proyecte establecerlos", $R D U, 16,(1970)$.

J. FERNÁNDEZ ÁLVAREZ, "El turismo como objeto del Derecho", RET, 43, (1974).

"Competencias en materia turística de las Comunidades Autónomas (reflexiones sobre la sentencia 125/1984, de 20 de diciembre del Tribunal Constitucional)", RET, 85, (1985).

S. FERNÁNDEZ RAMOS, "El Régimen Jurídico del municipio turístico en Andalucía. El Derecho a la carta", RAAP, 52, (2003).

C. FERNÁNDEZ RODRÍGUEZ, "La compleja integración normativa de la reciente planificación turística”, $D A, 259-260$, (2001).

J. FERREIRA FERNÁNDEZ y A. NOGUEIRA LÓPEZ, "Turismo y Ambiente: Legislación Autonómica y nuevas técnicas para un desarrollo sostenible", RArAP, 13, diciembre, (1998).

“Aspectos Jurídicos de un desarrollo turístico sostenible”, DA, 259-260, (2001).

J. FUSTER LAREU, “El municipio turístico español”, ICE, 421, (1968).

M. J. GALLARDO CASTILLO, "La Ordenación Jurídico-Administrativa del Turismo", RAAP, 25, (1996).

"La distribución constitucional de competencias en materia de turismo y su tratamiento en las Leyes Autonómicas: su promoción y ordenación", $D A$, 259-260, (2001).

M. GARCÍA CUADRILLO y A. LUIS GÓMEZ, "La legislación turística española y la configuración del camping como modalidad de alojamiento desde la perspectiva de cantabria (1956-1992)", RET, 119-120, (1993).

P. GARCÍA ROMERA, "Suspensión de licencias por revisión de un Plan de Ordenación Urbana de un Centro de Interés Turístico", Anales de la Dirección General de lo Contencioso del Estado, (66-73), I, (1975). 
A. GARCÍA-TREVIJANO FOS, "Contratos y actos ante el Tribunal Supremo: La explotación del Hotel Andalucía Palace, de Sevilla”, RAP, 28, (1959).

D. C. GILBERT, "Perspectivas de desarrollo del Turismo Rural", Revista Valenciana d'Estudis Autonomics, 13, (1992).

J. L. GONZÁLEZ-BERENGUER Y URRUTIA, "Urbanismo y turismo en el Derecho español”, Revista de Derecho Administrativo y Fiscal, La Coruña, 34, (1973).

A. GUAITA MARTOREL, "Organización Administrativa del Turismo en España”, Revista Temis de la Facultad de Derecho de Zaragoza, 24, (1968).

J. GUILLÉN CARAMÉS, “Algunos aspectos de la protección jurídica del turista”, REDA, 115, (2002).

O. HERRAIZ SERRANO, "El aprovechamiento turístico de las vías pecuarias", RArAP, Monográfico, (1999).

C. HORNO OCTAVIO, "La visión institucional de la política turística", RArAP, Monográfico, (1999).

R. M. ILDEFONSO HUERTAS, "Las políticas de turismo en la Comunidad Autónoma de Andalucía”, RAAP, número extraordinario, 2-volumen II, (2003).

Ma. I. JÁIMEZ GAGO, "El Plan General sobre el turismo de Andalucía”, RAAP, 52, (2003).

F. JURDAO ARRONES, "El municipio turístico", Boletín de Información de la Vida Local, 63, (1973).

F. LAURET, "Notas al planeamiento turístico", Boletín de Información de la Vida Local, 49, (1972).

A. LÁZARO, "La Administración en materia turística: evolución histórica y competencias en el ámbito provincial”, Boletín del Gobierno, 34, (1965).

M. I. LIROLA DELGADO, "Reflexiones en torno a una Política Comunitaria del Turismo", Revista de Instituciones Europeas, (1988). 
F. LÓPEZ RAMÓN, "Contrastes y conexiones de la moderna consideración del medio ambiente en la legislación turística”, RArAP, Monográfico, (1999).

F. LLISET BORREL, "Un régimen especial para los Municipios Turísticos", CAJ, 36, (1970).

"Mancomunidad turística en la Sierra de Huelva", Boletín de Información de la Vida Local, 16, Madrid, (1969).

M. MARTÍN FORNOZA, "El acto turístico. Estudios sobre un proyecto de ley de competencias en materias turísticas", RET, 21, (1969).

P. MARTÍNEZ ESPÍN, "Las relaciones jurídicas entre consumidores y empresas turísticas en la Ley de Turismo de Castilla-La Mancha", Revista Jurídica de Castilla-La Mancha, 30, (2001).

E. MARTÍNEZ JIMÉNEZ, "Los centros de turismo activo ante el reto de la gestión medioambiental", Revista Internacional Papers de Turisme, 34, (2004).

M. MONTORO PUERTO, "El Procedimiento Administrativo en la declaración de Centros y Zonas de Interés Turístico Nacional”, REVL, 156, (1967).

J. de los MOZOS y F. SAINZ DE ROBLES, "Limitaciones y modificaciones de los derechos reales inmobiliarios por razón de turismo", $R D U, 6$, (1968).

A. NOGUEIRA LÓPEZ, "La Ordenación del territorio y los recursos turísticos”, RArAP, Monográfico, (1999).

A. ORTEGA GARCÍA, "Aplicación de la Ley del Suelo a la tramitación de Planes de Ordenación urbana de Centros Turísticos”, $R D U$, 16, (1970).

J. ORTIZ DE MENDÍVIL, "El concepto jurídico de hospedaje", RET, 28, (1970).

G. E. PALACIO Y DE MONTEMAYOR, "Régimen Jurídico del Turismo Rural", RArAP, 14, (1999).

R. PÉREZ GUERRA, "La intervención administrativa en la clasificación de los establecimientos hoteleros: estudio comparativo en el Derecho turístico español”, $D A, 259-260$, (2001). 
R. PÉREZ GUERRA y M. M. CEBALLOS MARTÍN, "Reflexiones sobre el régimen jurídico-administrativo de las competencias en materia de turismo y de otros títulos que pueden incidir sobre el mismo", Revista Internacional Papers de Turisme, 19, (1995).

"A vueltas con el Régimen Jurídico-Administrativo de la distribución de competencias en materia de turismo y de otros títulos que inciden directamente sobre el mismo: el ejercicio de las competencias turísticas por la Comunidad Autónoma Andaluza”, RAAP, 27, julio-septiembre, (1996).

R. PÉREZ GUERRA y M. M. CEBALLOS MARTÍN, "Relación de disposiciones de Derecho del Turismo Español dictadas a lo largo del siglo XX" (Documentación), DA, 259-260, (2001).

L. PIDAL RODRIGÁLVEZ, "Aspectos jurídico y social del turismo español”, RET, 2, (1964).

B. PIÑAR, "Derecho turístico inmobiliario: problemas de titularidad, documentación y servidumbres", $A D C, 19$, (1962).

L. POMED SÁNCHEZ, "El patrimonio cultural factor de desarrollo local: los parques culturales”, RArAP, Monográfico, (1999).

G. PORRAS OLALLA, "La promoción del turismo en el marco de la Unión Europea”, RET, 152, (2002).

M. M. RAZQUÍN LIZÁRRAGA, "El marco jurídico de la restauración”, RArAP, Monográfico, (1999).

"La ordenación jurídica del Turismo en Navarra", RJN, 35, (2003).

M. REBOLLO PUIG, "Legislación Autonómica de Disciplina Turistica”, RAAP, 8, 1991.

J. L. RIVERO YSERN, "Notas sobre la Ley 12/1999, de 15 de diciembre, reguladora del turismo en Andalucía”, DA, 259-260, (2001).

A. ROBLES ÁLVAREZ DE SOTOMAYOR, "El contrato de alojamiento turístico", RET, 20, (1968).

"La Ley de Propiedad Horizontal y la explotación empresarial de alojamientos turísticos", RET, 27, (1970). 
E. ROCA ROCA, “Administración Pública y Turismo”, DA, 259-260, (2001).

“Aspectos jurídico-sociales de El diablo cojuelo", Boletín de la Real Academia de Córdoba, de Ciencias, Bellas Letras y Nobles Artes, LXVI, 129, (1995).

"Campos de golf y ordenación del territorio: régimen jurídico", $R D U, 165$, (1998).

"El turismo y el Estatuto de Autonomía de Andalucía", RAAP, número extraordinario, 2-volumen II, (2003).

R. RODRÍGUEZ DE LEÓN GARCÍA, "Una aproximación a la Ley del Turismo de Andalucía", RAAP, número extraordinario, 2-volumen II, (2003).

J. RODRÍGUEZ-ARANA MUÑOZ, "La distribución de competencias en materia de turismo", $D A, 259-260$, (2001).

C. RUIZ DEL CASTILLO Y CATALÁN DE ODÓN, "Aspectos socio-legales y administrativos del turismo", REVL, 143, (1965).

M. SANTAELLA LÓPEZ, "Problemas urbanísticos en los municipios turísticos”, $R D U, 32$, (1973).

J. SÁNCHEZ ISAC, "Planeamiento y programación de una promoción turística comarcal en el Alto Berguedá (Barcelona)”, REVL, 167, (1970).

M. J. SARMIENTO ACOSTA, "El Régimen especial del Municipio Turístico", Actualidad Administrativa, 45/5, 11 de diciembre de (1994).

A. SALGADO CASTRO, "La distribución de competencias en materia de turismo", RArAP, 9, (1996).

"La dimensión turística del patrimonio cultural", RArAP, Monográfico, (1999).

C. SÁNCHEZ CALVO, "El control de viajeros en establecimientos hoteleros y extrahoteleros", Boletín del Gobierno, 58, (1971).

J. SÁNCHEZ ISAC, "Planeamiento y programación de una promoción turística comarcal en el Alto Berguedá", REVL, 167, (1970). 
M. SANTAELLA LÓPEZ, "Problemas urbanísticos en los municipios turísticos", $R D U, 32$, (1973).

E. SANZ PAREJA, "La infraestructura turística en los municipios", El Alcalde, $17,(1968)$.

J. SOCIAS CAMACHO, "Regulación de las zonas turísticas en el Plan Insular de Ordenación de Gran Canaria (En especial, análisis de la situación transitoria)", RArAP, 9, (1996).

"Evolución de la Legislación Turística en las Islas Baleares", RArAP, 13, diciembre, (1998).

"La incidencia del turismo en la Ordenación del litoral (referencia especial al caso de las Islas Baleares)", RArAP, Monográfico, (1999).

A. de SOUZA IGLESIAS, "Análisis normativo de la Política de Turismo Rural en Canarias", RET, 134, (1997).

J. TUDELA ARANDA, "Hacia un nuevo Régimen Jurídico del Turismo: La reciente Legislación Autonómica”, RVAP, 45-I, (1996).

"El significado y función de los recursos turísticos en la nueva Legislación Turística”, RArAP, Monográfico, 1999.

“Turismo de montaña y estaciones de esquí", RArAP, Monográfico, (1999).

"La Ley y el Reglamento en el Derecho del Turismo", DA, 259-260, (2001).

"Un nuevo Derecho para un nuevo Turismo", RArAP, 24, (2004).

E. VALDÉS DEL FRESNO, "La Presidencia española de la Unión Europea en materia de Turismo", RET, 152, (2002).

M. VALENZUELA RUBIO, "La residencia secundaria en la provincia. Madrid, génesis y estructura espacial”, Ciudad y Territorio, 2-3, Madrid, (1976).

"Turismo y gran ciudad. Una opción de futuro para las metrópolis postindustriales", Revista Valenciana d'Estudis Autonomics, 13, (1992). 
J. C. VILLACORTA, "Yo he visto nacer un municipio turístico", El Alcalde, 17, (1968).

F. VILLALBA PÉREZ, "Aspectos constitucionales, legales y organizativos del turismo en Andalucía”, RAAP, número extraordinario, 2-volumen II, (2003).

\section{Repertorios bibliográficos.}

Q. FERNÁNDEZ ARROYO, "Bibliografía sobre turismo", DA, 162, (1974).

F. GONZÁLEZ NAVARRO, Derecho Administrativo y Ciencia de la Administración, repertorio bibliográfico de autores españoles, 1976 (apartado sobre turismo).

Bibliografía sobre derecho urbanistico, Montecorvo, Madrid, 1981 (apartado sobre turismo).

A. GUAITA MARTORELL, Nueva bibliografía española de Derecho Administrativo, 1969 (apartado sobre turismo).

E. ORDUÑA REBOLLO, Bibliografía Iberoamericana de Administración Local, IEAL, Madrid, 1983 (apartado sobre turismo).

\section{Obras generales de Derecho Administrativo.}

J. BERMEJO VERA (Dir.), Derecho Administrativo. Parte Especial, $5^{\underline{a}}$ ed., ed. Cívitas, Madrid, 2001 (de manera especial el capítulo VII de la Parte V, titulado "El turismo", dentro de la Regulación de los sectores, realizada por A. GARCÉS SAN AGUSTÍN, pp. 1028 a 1064).

A. GUAITA MARTORELL, Derecho Administrativo Especial, Librería General, Zaragoza, 1966 (T. IV, pp. 129 a 145), 1970 (T. IV, pp. 133 a 151).

L. JORDANA DE POZAS, "Actividades y servicios de la Administración Local relacionados con el turismo", en Problemas Políticos de la Vida Local, T.V., Delegación Nacional de Provincias del Movimiento, Madrid, 1965.

F. ROMERO HERNÁNDEZ, La actividad turística de los municipios, en Derecho Local, T. II, ed. Abella, Madrid, 1999. 


\section{Comentarios a la Constitución Española.}

F. CASTILLO BLANCO, "Artículo 148. Competencias de las Comunidades Autónomas", en O. ALZAGA VILLAMIL (Dir.), Comentarios a la Constitución Española de 1978. Cortes Generales, ed. Edersa, 2ª ed., Madrid, 1999.

\section{Comentarios a Estatutos de Autonomía.}

P. ESCRIBANO COLLADO, "Artículo 13.17: Promoción y ordenación del turismo”, en S. MUÑOZ MACHADO (Dir.), Comentarios al Estatuto de Andalucía, Ministerio para las Administraciones Públicas-IEL, Madrid, 1987.

A. PÉREZ MORENO, P. ESCRIBANO COLLADO, J.L. RIVERO ISERN, J.I. LÓPEZ GONZÁLEZ, J.I. MORILLO-VELARDE PÉREZ y F. LÓPEZ MENUDO, Comentarios al Estatuto de Andalucía, Instituto García Oviedo, Sevilla, 1981.

\section{Comentarios a la Ley Reguladora de las Bases de Régimen Local.}

J. GALOFRE CRESPI, "Regímenes municipales especiales", en AA.VV, Comentarios a la Ley de Bases de Régimen Local, CEUMT, Madrid, 1987, pp. 75 y 76 .

\section{Obras de Derecho Administrativo del Turismo.}

R. ARCARÓNS SIMÓN, Manual de Derecho Administrativo Turístico, 2ª ed., ed. Síntesis, Madrid, 1999.

J. I. de ARRILLAGA, El turismo, Instituto de Estudios Políticos, IEP: El nuevo estado español, 1963.

Sistema de Política Turística, ed. Aguilar, Madrid, 1955.

Manual de Legislación Administrativa Turística, $2^{\underline{a}}$ ed., ed. Instituto de Estudios Turísticos, Madrid, 1976.

D. BLANQUER CRIADO, Derecho del Turismo, ed. Tirant lo Blanch, Valencia, 1999. 
El golf: mitos y razones sobre el uso de los recursos naturales. Ordenación del territorio, espacios de ocio y desarrollo rural, ed. Tirant lo Blanch, Valencia, 2002.

D. BLANQUER CRIADO (Dir.), Ordenación y gestión del territorio turístico, ed. Triant lo Blanch, Valencia, 2002.

J. BONET CORREA, La Legislación Turística comparada y su evolución, Colección Cuadernos Monográficos, núm. 2, ed. Instituto de Estudios Turísticos, Madrid, 1965.

A. CALONGE VELÁZQUEZ, El Turismo: Aspectos Institucionales y Actividad Administrativa, ed. Servicio de Publicaciones de la Universidad de Valladolid, Valladolid, 2000.

Mª . M. CEBALLOS MARTÍN, La regulación jurídica de los Establecimientos Hoteleros, (declarado "Libro de Interés Turístico Nacional"), ed. Marcial Pons, Madrid, 2002.

M. M. CEBALLOS MARTÍN y R. PÉREZ GUERA, El Contrato Turístico de Alojamiento Hotelero, (declarado "Libro de Interés Turístico nacional"), 1a edición, Servicio de Publicaciones de la Universidad de Almería, Almería 2000, 2ª edición, ed. Comares, Granada, 2001.

R. de la CIERVA Y DE HOCES, Turismo. Teoría. Técnica. Ambiente, Ed. River, Madrid, 1963.

L. CORRALES BERMEJO y J.L. RIVAS ZURDO, Estudio de la normativa autonómica sobre Turismo Rural, Fundación Cultural Santa Teresa, Ávila, 1993.

J. DIETTA, Los organismos colegiados del Ministerio de Información y Turismo. Composición y funciones, ed. Secretaría General Técnica, Ministerio de Información y Turismo, Madrid, 1964.

F. DOMÍNGUEZ MOLINER, Derecho Administrativo y Legislación Turística, ed. Ramón Areces, Madrid, 2000.

J. FERNÁNDEZ ÁLVAREZ, Curso de Derecho Administrativo Turístico, (4 vol.), Editora Nacional, Madrid, vol. I y II, 1974, vol. III, 1977 y vol. IV, 1980.

C. FERNÁNDEZ RODRÍGUEZ, Derecho Administrativo del Turismo, 2ª ed., ed. Marcial Pons, Madrid, 2003. 
R. GARCÍA MACHO, A. RECALDE CASTELLS (y otros), Lecciones de Derecho del Turismo, ed, Tirant lo Blanch, Valencia, 2000.

J. LUENGO YUSTE, Legislación Turística y Derecho Administrativo, ed. Univérsitas, Madrid, 1992.

J. L. MEILÁN GIL, Empresas Públicas y Turismo, ed. Escuela Nacional de Administración Pública, Madrid, 1967.

J. L. MEILÁN GIL, J. RODRÍGUEZ-ARANA MUÑOZ (y otros), Estudios Jurídicos sobre el Camino de Santiago, Fundación Instituto Gallego de Estudios Autonómicos y Comunitarios, Santiago, 1994.

R. NASARRE ALAS TRUEY, Las urbanizaciones particulares. La Ley del Suelo ante el fenómeno turístico, ed. Aranzadi, Pamplona, 1970.

J. ORTIZ DE MENDIVIL, Derecho del Turismo, Estudios Administrativos, ed. Escuela Nacional de Administración Pública, Madrid, 1971.

E. PÉREZ BONÍN, Tratado Elemental de Derecho Turístico, ed. Daimon, México, 1978.

J. M. PÉREZ FERNÁNDEZ, Régimen Jurídico del Turismo Rural, Tribuna Jorge Vila Fradera-AECIT, ed, Feria Internacional de Turismo-AECIT, Madrid, 2001.

J.M. PÉREZ FERnÁNDEZ (Dir.), Derecho Público del Turismo, ed. ThomsonAranzadi, Elcano, 2004.

R. PÉREZ GUERRA, El régimen jurídico-administrativo del turismo: organización y competencias, Servicio de Publicaciones de la Universidad de Almería, 1999.

R. PÉREZ GUERRA y Mํ. M. CEBALLOS MARTÍN, El contrato turístico de alojamiento hotelero, (declarado "Libro de Interés Turístico Nacional"), ed. Comares, Granada, 2001.

La intervención Administrativa en la clasificación de los establecimientos hoteleros, (declarado "Libro de Interés Turístico Nacional"; Trabajo premiado por la Real Academia de Jurisprudencia y Legislación de Granada, en junio de 2000 y patrocinado por la familia de D. José Luis Pérez-Serrabona Sanz), ed. Comares, Granada, 2001. 
"Reflexiones sobre la ordenación legislativa de las Comunidades Autónomas en 1998”, en La actividad turística española en 1998, ed. Asociación Española de Expertos Científicos en Turismo y Universidad de Almería, Madrid, 1999, pp. 447 a 453.

"Estudio comparativo de la ordenación en la clasificación hotelera", en La actividad turística española en 1998, ed. Asociación Española de Expertos Científicos en Turismo, Madrid, 2000, pp. 431 a 445.

R. PÉREZ GUERRA (Coord.), M. M. CEBALlos MARTÍN, y M. L. ROCA FERNÁNDEZ-CASTANYS, Derecho de las actividades turísticas, ed. Fundación de la Universidad Oberta de Cataluña-ed. Planeta, Barcelona, 2003.

Dret de les activitats turístiques, ed. Fundación de la Universidad Oberta de Cataluña-ed. Planeta, Barcelona, 2003.

M. ${ }^{a}$ L. ROCA FERNÁNDEZ-CASTANYS, Aprovechamiento turístico de los espacios naturales protegidos. Régimen jurídico, Servicio de Publicaciones de la Consejería de Turismo, Comercio y Deporte de la Junta de Andalucía, Sevilla, 2005.

E. ROCA ROCA, Estudio Turístico de la Costa del Sol de Granada, ed. Delegación Provincial de Sindicatos, Granada, 1967.

E. ROCA ROCA, M. M. CEBALLOS MARTÍN, y R. PÉREZ GUERRA, La $R \boldsymbol{e}^{-}$ gulación Jurídica del Turismo en España, (declarado "Libro de Interés Turístico Nacional"), ed. Servicio de Publicaciones de la Universidad de Almería, Almería, 1998.

C. SANZ DOMÍNGUEZ, Régimen jurídico del Turismo en el espacio rural: análisis y compendio normativo, 2 vol., ed. Servicio de Publicaciones de la Consejería de Turismo y Deporte de la Junta de Andalucía, Sevilla, 2002.

J. M. SOCIAS CAMACHO, La ordenación de las zonas turísticas litorales, Instituto Pascual Madoz, Universidad Carlos III de Madrid y Boletín Oficial del Estado, Madrid, 2001.

L. VALDÉS PELÁEZ y J.M. FERNÁNDEZ PÉREZ (Dirs.), Experiencias públicas y privadas en el desarrollo de un modelo de turismo sostenible, Fundación Universitaria de Oviedo, Oviedo, 2003. 


\section{Libros homenaje.}

J. F. ALENZA GARCÍA, "Turismo y caminos de la naturaleza", en Panorama jurídico de las Administraciones Públicas en el siglo XXI, Libro homenaje al Prof. Eduardo Roca Roca, INAP-BOE, Madrid, 2002.

M. P. BENSUSAN MARTÍN, "Vías pecuarias y turismo rural: un binomio a potenciar”, en Panorama jurídico de las Administraciones Públicas en el siglo XXI, Libro homenaje al Prof. Eduardo Roca Roca, INAP-BOE, Madrid, 2002.

D. BLANQUER CRIADO, "El Derecho Administrativo en el umbral del siglo XXI”, en Libro Homenaje al Prof. Ramón Martín Mateo, ed. Tirant lo Blanch, Valencia, 2000.

Mª . M. CEBALLOS MARTÍN y R. PÉREZ GUERRA, "Aproximación evolutiva en la protección de los recursos naturales y culturales a través de la legislación turística”, Panorama jurídico de las Administraciones Públicas en el siglo XXI, en Libro homenaje al Prof. Eduardo Roca Roca, INAP-BOE, Madrid, 2002.

U. FRAGOLA, "La disciplina jurídica del comercio turístico en Italia respecto a la legislación española”, en Libro homenaje al Prof. Laureano López Rodó, T. II, Madrid, 1972.

J. PÉREZ MARTOS, "La regulación comunitaria del turismo”, en Panorama jurídico de las Administraciones Públicas en el siglo XXI, Libro homenaje al Prof. Eduardo Roca Roca, INAP-BOE, Madrid, 2002.

\section{Actas de Congresos, Seminarios y Jornadas de Estudio.}

A. ALCALDE INCHAUSTI, "Problemas estadísticos de las urbanizaciones turísticas”, en Problemas técnicos, económicos y jurídicos de urbanización de zonas turísticas, curso de conferencias (Tarragona, 1964), 3 vols, Madrid, 1965.

F. ALENZA GARCÍA, "Turismo y Derecho Ambiental, con especial referencia al turismo en espacios naturales”, en III Congreso de Turismo Universidad y Empresa, celebrado los días 4 a 6 de abril de 2000, en Benicassim, Castellón, ed. Tirant lo Blanch, Valencia, 2000.

C. ÁLVAREZ ROMERO, "La Ley sobre Centros y Zonas de interés turístico nacional y el Registro de la Propiedad", en Problemas técnicos, económicos y ju- 
rídicos de urbanización de zonas turísticas, curso de conferencias (Tarragona, 1964), 3 vols, Madrid, 1965.

A. ANDREU MASSO, "La ordenación de una gran ciudad como meta de una zona turística", en I Congreso Nacional de Urbanismo, 1962.

L. R. ARREGUI LUCEA, "Los planes de extensión turístico-residencial en el Área Metropolitana de Madrid", en V Congreso Hispano-Luso-Americano-Filipino de Municipios.

E. BASSOLS MONTSERRAT, "La promoción del turismo en la Administración”, en el vol. colectivo Problemas políticos de la vida local, XII, Madrid, 1972.

D. BLANQUER CRIADO, "La publificación del contrato de hospedaje", en Actas del I Congreso Universitario de Turismo, celebrado los días 27 a 29 de octubre de 1998 en Peñíscola, Castellón, ed. Tirant lo Blanch, Valencia, 1999.

"Régimen Jurídico del Turismo Rural", en Actas del II Congreso de Turismo Universidad y Empresa, celebrado los días 21 a 23 de abril de 1999 en Benicássim, Castellón, ed. Tirant lo Blanch, Valencia, 2000.

"Fiestas populares y responsabilidad patrimonial del municipio", en III Congreso de Turismo Universidad y Empresa, celebrado los días 4 a 6 de abril de 2000, en Benicassim, Castellón, ed. Tirant lo Blanch, Valencia, 2000.

"Potestad reglamentaria y Derecho Privado; protección del turista y contrato de hospedaje; réplica", en III Congreso de Turismo Universidad y Empresa, celebrado los días 4 a 6 de abril de 2000, en Benicassim, Castellón, ed. Tirant lo Blanch, Valencia, 2000.

J. L. BLASCO DÍAZ, "Régimen Jurídico de las actividades turísticas desarrolladas sobre el litoral", en Actas del I Congreso Universitario de Turismo, celebrado los días 27 a 29 de octubre de 1998 en Peñíscola, Castellón, ed. Tirant lo Blanch, Valencia, 1999.

"La ordenación territorial y la protección de valores naturales del litoral. El proyecto de la nueva Ley de Ordenación del Territorio de la Comunidad Valenciana", en Actas del II Congreso de Turismo Universidad y Empresa, celebrado los días 21 a 23 de abril de 1999 en Benicássim, Castellón, ed. Tirant lo Blanch, Valencia, 2000. 
M. T. CABEZAS HERNÁNDEZ, "Europa, las regiones y el Derecho del Turismo", en Actas del I Congreso sobre Derecho Administrativo Turístico, celebrado en Cáceres los días 16 a 20 de octubre de 2000, Servicio de Publicaciones de la Universidad de Extremadura, Cáceres, 2002.

A. CALONGE VELÁZQUEZ y H. VILLAREJO GALENDE, "Municipios Turísticos y horarios comerciales", en III Congreso de Turismo Universidad y Empresa, celebrado los días 4 a 6 de abril de 2000, en Benicássim, Castellón, ed. Tirant lo Blanch, Valencia, 2000.

J. M. CASTELLS ARTECHE y E. M. LÓPEZ TUBIA, "Comarca turística versus consorcio turístico. La ordenación del agroturismo en el Territorio Histórico de Guipúzcoa”, en III Congreso de Turismo Universidad y Empresa, celebrado los días 4 a 6 de abril de 2000, en Benicassim, Castellón, ed. Tirant lo Blanch, Valencia, 2000.

I. CARO-PATON CARMONA, "Usos Turísticos de los cursos de agua", en III Jornadas sobre Derecho y Turismo, celebradas los días 8 a 10 de noviembre de 1996 en Ávila, ed. Fundación Cultural Santa Teresa, Ávila, 1999.

M. M. CEBALLOS MARTÍN y R. PÉREZ GUERRA, "El régimen jurídico-administrativo de Paradores de Turismo de España”, en Actas del II Congreso de Turismo Universidad y Empresa, celebrado los días 21 a 23 de abril de 1999 en Benicássim, Castellón, ed. Tirant lo Blanch, Valencia, 2000.

"Reflexiones sobre la ordenación legislativa de las Comunidades Autónomas: sus Leyes de Turismo”, en III Jornadas de Derecho Turístico, celebradas lo días 10, 11 y12 de mayo de 2000, en Málaga, ed. Servicio de Publicaciones de la Consejería de Turismo y Deporte de la Junta de Andalucía, Sevilla, 2000.

"El régimen jurídico del Turismo Rural: análisis del Decreto andaluz de 29 de enero de 2002”, en VII Congreso AECIT, celebrado en Jaén los días 21 a 23 de octubre de 2002, ed. AECIT, Madrid, 2003.

A. F. CORREA VEGLISON, "Urbanizaciones (en zonas turísticas)", en Problemas técnicos, económicos y jurídicos de urbanización de zonas turísticas, curso de conferencias (Tarragona, 1964), vol. III, Madrid, 1965.

J. M. DE LA CUÉTARA MARTÍNEZ, "Los poderes públicos ante el sector turístico”, en El Turismo en Canarias, IV Jornadas de Estudios Económicos Canarios, Colección Viera y Clavijo, 1985. 
R. CUSCO TARDIU, "Centros de turismo invernal, derivados de la práctica del esquí. Su importancia y evolución futura”, en Problemas técnicos, económicos y juridicos de urbanización de zonas turísticas, curso de conferencias (Tarragona, 1964), vol. II, Madrid, 1965.

M. DIEZ DE VELASCO VALLEJO, "Reflexiones sobre el turismo y el desarrollo del medio ambiente en la Unión Europea", en Actas del II Congreso de Turismo Universidad y Empresa, celebrado los días 21 a 23 de abril de 1999 en Benicássim, Castellón, ed. Tirant lo Blanch, Valencia, 2000.

M. DOMÍNGUEZ-BERRUETA DE JUAN y P. T. NEVADO-BATALLA MORENO, "El ejercicio de la potestad sancionadora en el sector turístico. Análisis a la luz de la Ley 10/1997, de 19 de diciembre, de Turismo de Castilla y León”, en III Jornadas sobre Derecho y Turismo, celebradas los días 8 a 10 de noviembre de 1996 en Ávila, ed. Fundación Cultural Santa Teresa, Ávila, 1999.

J. ESTEVE PARDO, “Turismo y Administración Local”, en XI Congreso ItaloEspañol de Profesores de Derecho Administrativo, celebrado los días 26 a 28 de septiembre de 1996, en Barcelona-Girona, ed CEDECS, Barcelona, 1998.

J. FERNÁNDEZ ÁLVAREZ, "La Ley de Centros y zonas de interés turístico nacional”, en Problemas técnicos, económicos y jurídicos de urbanización de zonas turísticas, curso de conferencias (Tarragona, 1964), vol. II, Madrid, 1965.

D. FERNÁNDEZ DE GATTA SÁNCHEZ, "La Política Turística de la Unión Europea”, en III Jornadas sobre Derecho y Turismo, celebradas los días 8 a 10 de noviembre de 1996 en Ávila, ed. Fundación Cultural Santa Teresa, Ávila, 1999 .

A. J. GARCÍA RODRÍGUEZ-ACOSTA, "El turismo local", en el vol. colectivo Problemas políticos de la vida local, IV, Madrid, 1964.

J. GONZÁLEZ PAZ, "Promoción de zonas turísticas. Su incidencia en la economía regional y en las Haciendas provinciales y locales", en Problemas técnicos, económicos y jurídicos de urbanización de zonas turísticas, curso de conferencias (Tarragona, 1964), vol. I, Madrid, 1965.

"Planeamiento económico de las urbanizaciones turísticas privadas", en Problemas técnicos, económicos y jurídicos de urbanización de zonas turísticas, curso de conferencias (Tarragona, 1964), vol. I, Madrid, 1965. 
M. A. GRIFO BENEDICTO, "Colaboración interadministrativa en turismo: mancomunidades, consorcios, conferencias sectoriales y convenios de colaboración”, en Actas del I Congreso Universitario de Turismo, celebrado los días 27 a 29 de octubre de 1998 en Peñíscola, Castellón, ed. Tirant lo Blanch, Valencia, 1999.

A. GUAITA MATORELL, "La actividad de los particulares en los Centros y Zonas de Interés Turístico Nacional”, en I Congreso Italo-Español de Profesores de Derecho Administrativo, celebrado los días 17 y 18 de mayo de 1966 en Sevilla, ed. Servicio de Publicaciones del Ministerio de Información y Turismo, Madrid, 1970.

M. A. GUILLÉN GALINDO, "La distribución de competencias en materia turística entre el Estado, las Comunidades Autónomas y las Entidades Locales. Especial referencia a la Comunidad Valenciana", en Actas del I Congreso Universitario de Turismo, celebrado los días 27 a 29 de octubre de 1998 en Peñíscola, Castellón, ed. Tirant lo Blanch, Valencia, 1999.

C. GUISASOLA LERMA, "Turismo cultural y preservación del patrimonio histórico y su entorno", en Actas del II Congreso de Turismo Universidad y Empresa, celebrado los días 21 a 23 de abril de 1999 en Benicássim, Castellón, ed. Tirant lo Blanch, Valencia, 2000.

J. JANE SOLA, "Creación de centros comerciales en las urbanizaciones turísticas", en Problemas técnicos, económicos y jurídicos de urbanización de zonas turísticas, curso de conferencias (Tarragona, 1964), vol. II, Madrid, 1965.

O. HERRAIZ SERRANO, "El turismo y la conservación de las vías pecuarias", en Actas del II Congreso de Turismo Universidad y Empresa, celebrado los días 21 a 23 de abril de 1999 en Benicássim, Castellón, ed. Tirant lo Blanch, Valencia, 2000.

L. JORDANA DE POZAS, "Actividades y servicios de la Administración Local relacionados con el turismo", en Problemas Políticos de la Vida Local, T.V., Delegación Nacional de Provincias del Movimiento, Madrid, 1965.

M. LACASA SUÁREZ-INCLÁN, "Planificación turística de las Islas Canarias", en Problemas técnicos, económicos y jurídicos de urbanización de zonas turísticas, curso de conferencias (Tarragona, 1964), vol. III, Madrid, 1965.

V. LAFUENTE FONTANA, "Problemas de la infraestructura del saneamiento en relación con las zonas turísticas”, en Problemas técnicos, económicos y juri- 
dicos de urbanización de zonas turísticas, curso de conferencias (Tarragona, 1964), vol. II, Madrid, 1965.

C. LÓPEZ Y LÓPEZ, "Fórmulas asociativas con participación municipal para la promoción turística de la Mancha", en XIV Congreso Interamericano de Municipios, celebrado en Málaga en 1972, ed. IEAL, Madrid, 1973.

M. MARÍN HERRERA, "La Administración institucional del turismo", en Actas del I Congreso Universitario de Turismo, celebrado los días 27 a 29 de octubre de 1998 en Peñíscola, Castellón, ed. Tirant lo Blanch, Valencia, 1999.

R. MARTÍN MATEO, L. MARTÍN RETORTILLO y J. L. VILLAR PALASÍ, “Aspectos jurídicos-administrativos del turismo", en I Congreso Italo-Español de Profesores de Derecho Administrativo, celebrado los días 17 y 18 de mayo de 1966 en Sevilla, ed. Servicio de Publicaciones del Ministerio de Información y Turismo, Madrid, 1970.

E. MARÍNEZ JIMÉNEZ, "Los espacios naturales sometidos a un régimen especial de protección ambiental como destino turístico", en VI Congreso AECIT. Nuevas Tecnologías de Ocio y Turismo: su especial problemática en destinos singulares, AECIT, Jaén, 2002.

"Los instrumentos de ordenación de los usos turísticos en los espacios sometidos a un régimen especial de protección ambiental", en $V$ Congreso de Turismo, Universidad y Empresa. La calidad integral de turismo, ed. Tirant lo Blanch, Valencia, 2003.

J. L. MEILÁN GIL, "Las empresas públicas de hostelería en el derecho español”, en I Congreso Italo-Español de Profesores de Derecho Administrativo, celebrado los días 17 y 18 de mayo de 1966 en Sevilla, ed. Servicio de Publicaciones del Ministerio de Información y Turismo, Madrid, 1970.

F. J. MELGOSA ARCOS, "La ordenación del turismo rural: aspectos administrativos, fiscales y laborales”, en I Jornadas de Derecho Turistico, celebradas el día 21 de mayo de 1998, en Málaga, ed. Servicio de Publicaciones de la Consejería de Turismo y Deporte de la Junta de Andalucía, Sevilla, 1999.

“Campamentos de turismo. Régimen Jurídico en Castilla y León”, en III Jornadas sobre Derecho y Turismo, celebradas los días 8 a 10 de noviembre de 1996 en Ávila, ed. Fundación Cultural Santa Teresa, Ávila, 1999. 
"Turismo de salud: termalismo y balnearios", en III Congreso de Turismo Universidad y Empresa, celebrado los días 4 a 6 de abril de 2000, en Benicassim, Castellón, ed. Tirant lo Blanch, Valencia, 2000.

J. A. MELIÁN GARCÍA, “Administración Pública y Turismo”, en El Turismo en Canarias, IV Jornadas de Estudios Económicos Canarios, Colección Viera y Clavijo, 1985.

M. J. MONTORO CHINER, "Privado y público en los parques temáticos de ocio", en Actas del I Congreso Universitario de Turismo, celebrado los días 27 a 29 de octubre de 1998 en Peñíscola, Castellón, ed. Tirant lo Blanch, Valencia, 1999.

M. MONTORO PUERTO, "La Unión Turística del Pirineo", en I Congreso Italo-Español de Profesores de Derecho Administrativo, celebrado los días 17 y 18 de mayo de 1966 en Sevilla, ed. Servicio de Publicaciones del Ministerio de Información y Turismo, Madrid, 1970.

L. MORELL OCAÑA, "Realidad y problemas de los municipios turísticos", en III Congreso de Turismo Universidad y Empresa, celebrado los días 4 a 6 de abril de 2000, en Benicassim, Castellón, ed. Tirant lo Blanch, Valencia, 2000 .

R. E. MUÑOZ BLANCO, "La actividad administrativa en relación al ocio: en especial juegos y casinos", en Actas del I Congreso sobre Derecho Administrativo Turístico, celebrado en Cáceres los días 16 a 20 de octubre de 2000, Servicio de Publicaciones de la Universidad de Extremadura, Cáceres, 2002.

G. MUÑOZ GOYANES, "Valor turístico de los Parques Nacionales", en Problemas técnicos, económicos y jurídicos de urbanización de zonas turísticas, curso de conferencias (Tarragona, 1964), vol. I, Madrid, 1965.

A. M. NIETO-GUERRERO LOZANO, "La distribución competencial en materia turística. Especial referencia al nuevo papel, en la materia, de los entes locales y, concretamente, de los municipales", en Actas del I Congreso sobre Derecho Administrativo Turístico, celebrado en Cáceres los días 16 a 20 de octubre de 2000, Servicio de Publicaciones de la Universidad de Extremadura, Cáceres, 2002.

J. L. PALMA FERNÁNDEZ, "Ordenación jurídica de los Paradores de Turismo de España”, en Actas del I Congreso Universitario de Turismo, celebrado los 
días 27 a 29 de octubre de 1998 en Peñíscola, Castellón, ed. Tirant lo Blanch, Valencia, 1999.

M. PALOMARES CASADO, "Problemas meteorológicos de la urbanización de Zonas turísticas", en Problemas técnicos, económicos y jurídicos de urbanización de zonas turísticas, curso de conferencias (Tarragona, 1964), vol. I, Madrid, 1965.

"Problemas físicos de las urbanizaciones turísticas", en Problemas técnicos, económicos y jurídicos de urbanización de zonas turísticas, curso de conferencias (Tarragona, 1964), vol. I, Madrid, 1965.

J.M. PÉREZ FERNÁNDEZ, "La articulación de un modelo de planificación turística sostenible", en VI Congreso AECIT "Nuevas tendencias de ocio y turismo su especial problemática en destinos singulares”, celebrado en Jaén, AECIT, 2002.

"La ordenación integral de las actividades turísticas desarrolladas en el litoral: propuestas para la coordinación de los distintos instrumentos de planificación del Principado de Asturias", en V Congreso de Turismo Universidad y Empresa. La calidad integral de turismo, ed. Tirant lo Blanch, Valencia, 2003.

R. PÉREZ GUERRA y Ma..M. CEBALLOS MARTÍN, "Hacia la configuración del Estatuto del Municipio Turístico: estudio del proyecto de Decreto de Municipio Turístico de Andalucía”, en VI Congreso de la Asociación Española de Expertos Científicos en Turismo "Nuevas tendencias de Ocio y Turismo: sus especial problemática en destinos singulares” y I Simposium Internacional de Turismo, celebrado en Ceuta los días 27 y 28 de septiembre de 2001.

R. PÉrEZ GUERRA, M. M. CEBALLOS MARTÍN y J. PÉREZ MARTOS, “Turismo y Medio Ambiente: La necesaria articulación de dos ordenamientos sectoriales", I Congreso Internacional Turismo y Mediterráneo, celebrado en Almería los días 8 a 11 de febrero de 2000.

R. PÉREZ GUERRA, Maㅡ. M. CEBALLOS MARTÍN y Ma․ L. ROCA FERNÁNDEZ-CASTANYS, "La planificación de la actividad turística en los espacios naturales protegidos", en IV Congreso Andaluz de Turismo, celebrado en Jaén, los días 22 y 23 de noviembre de 2001.

A. PÉREZ MORENO, "La Regionalización del Turismo (solución a un problema de competencia)", en I Congreso Italo-Español de Profesores de Derecho 
Administrativo, celebrado los días 17 y 18 de mayo de 1966 en Sevilla, ed. Servicio de Publicaciones del Ministerio de Información y Turismo, Madrid, 1970.

F. PRIETO MORENO, "Ambientación paisajística de los Centros de Turismo", en Problemas técnicos, económicos y jurídicos de urbanización de zonas turísticas, curso de conferencias (Tarragona, 1964), vol. III, Madrid, 1965.

M. RAZQUÍN LIZÁRRAGA, "Organización local del turismo”, en III Congreso de Turismo Universidad y Empresa, celebrado los días 4 a 6 de abril de 2000, en Benicassim, Castellón, ed. Tirant lo Blanch, Valencia, 2000.

M. RIVAS Y PIERA, "Un ejemplo de plan territorial turístico: el estudio del Plan general de ordenación urbanística de la Isla de Ibiza", en Problemas técnicos, económicos y jurídicos de urbanización de zonas turísticas, curso de conferencias (Tarragona, 1964), vol. III, Madrid, 1965.

E. RIVERO YSERN, "La repercusión de la normativa de Centros y Zonas de Interés y su Reglamento, en el aprovechamiento, uso y disfrute de los bienes de las entidades municipales", en I Congreso Italo-Español de Profesores de Derecho Administrativo, celebrado los días 17 y 18 de mayo de 1966 en Sevilla, ed. Servicio de Publicaciones del Ministerio de Información y Turismo, Madrid, 1970.

J. L RIVERO YSERN, "El Municipio Turístico en la futura Ley del Turismo de Andalucía”, en I Jornadas de Derecho Turístico, celebradas el día 21 de mayo de 1998, en Málaga, ed. Servicio de Publicaciones de la Consejería de Turismo y Deporte de la Junta de Andalucía, Sevilla, 1999.

"Notas sobre el Municipio Turístico en la Ley 12/1999, de 15 de diciembre, Ley del Turismo de Andalucía”, en III Jornadas de Derecho Turístico, celebradas lo días 10, 11 y12 de mayo de 2000, en Málaga, ed. Servicio de Publicaciones de la Consejería de Turismo y Deporte de la Junta de Andalucía, Sevilla, 2000.

E. ROCA ROCA y J. PÉREZ MARTOS, "Administración Municipal y Turismo”, en XI Congreso Italo-Español de Profesores de Derecho Administrativo, celebrado los días 26 a 28 de septiembre de 1996, en Barcelona-Girona, ed CEDECS, Barcelona, 1998.

J.M. RODRÍGUEZ BARRIGÓN, "Algunas consideraciones sobre el turismo en la Unión Europea”, en Actas del I Congreso sobre Derecho Administrati- 
vo Turístico, celebrado en Cáceres los días 16 a 20 de octubre de 2000, Servicio de Publicaciones de la Universidad de Extremadura, Cáceres, 2002.

N. RODRÍGUEZ MORO, "La asociación de Municipios y de provincias para fines de interés turístico", en XIV Congreso Interamericano de Municipios, celebrado en Málaga, en 1972, ed. IEAL, Madrid, 1973.

M. RODRÍGUEZ-PIÑERO BRAVO-FERRER, "La intervención administrativa en la empresa hotelera", en I Congreso Italo-Español de Profesores de Derecho Administrativo, celebrado los días 17 y 18 de mayo de 1966 en Sevilla, ed. Servicio de Publicaciones del Ministerio de Información y Turismo, Madrid, 1970.

J. ROS HOMBRAVELLA, "Problemas para la formación de capital social y para los servicios públicos locales en las Zonas turísticas", en Problemas técnicos, económicos y jurídicos de urbanización de zonas turísticas, curso de conferencias (Tarragona, 1964), vol. II, Madrid, 1965.

A. SABÁN GODOY, "Administraciones Públicas y el sector turístico", en Actas del I Congreso sobre Derecho Administrativo Turístico, celebrado en Cáceres los días 16 a 20 de octubre de 2000, Servicio de Publicaciones de la Universidad de Extremadura, Cáceres, 2002.

F. C. SAINZ DE ROBLES, "Competencia municipal en la planificación turística, en vol. colectivo", Crónica del V Congreso Hispano-Luso-Americano-Filipino de Municipios, celebrado en Santiago de Chile en 1969, ed. IEAL, Madrid, 1970.

E. SANZ PAREJA, "Urbanizaciones turísticas en el litoral y la zona marítimoterrestre", en Problemas técnicos, económicos y jurídicos de urbanización de zonas turísticas, curso de conferencias (Tarragona, 1964), vol. II, Madrid, 1965.

I. SANZ RUBIALES, "Ley de costas y turismo", en III Jornadas sobre Derecho y Turismo, celebradas los días 8 a 10 de noviembre de 1996 en Ávila, ed. Fundación Cultural Santa Teresa, Ávila, 1999.

E. SECO GÓMEZ, "Turismo y ordenación del territorio", en Turismo en Canarias, IV Jornadas de Estudios Económicos Canarios, colección Viera y Clavijo, 1985. 
A. SERRA PIÑAR, "El crédito turístico", en I Congreso Italo-Español de Profesores de Derecho Administrativo, celebrado los días 17 y 18 de mayo de 1966 en Sevilla, ed. Servicio de Publicaciones del Ministerio de Información y Turismo, Madrid, 1970.

P. SERRADA Y GARCÍA-OLAZ, "Problemas jurídicos que plantea el traslado de industrias en la urbanización de Zonas turísticas", en Problemas técnicos, económicos y jurídicos de urbanización de zonas turísticas, curso de conferencias (Tarragona, 1964), vol. II, Madrid, 1965.

J. A. SOCIAS CAMACHO, "La reconversión de los destinos turísticos mediante el esponjamiento urbanístico y la modernización de alojamientos en las Islas Baleares", en III Congreso de Turismo Universidad y Empresa, celebrado los días 4 a 6 de abril de 2000, en Benicassim, Castellón, ed. Tirant lo Blanch, Valencia, 2000.

J. E. SORIANO GARCÍA, "Viajes y Derecho", en Actas del I Congreso sobre Derecho Administrativo Turístico, celebrado en Cáceres los días 16 a 20 de octubre de 2000, Servicio de Publicaciones de la Universidad de Extremadura, Cáceres, 2002.

J. SUAY RINCÓN y M. del P. RODRÍGUEZ GONZÁLEZ, "Las competencias turísticas de los municipios. En particular, la categoría de los municipios turísticos", en Actas del I Congreso Universitario de Turismo, celebrado los días 27 a 29 de octubre de 1998 en Peñíscola, Castellón, ed. Tirant lo Blanch, Valencia, 1999.

"Régimen jurídico-administrativo de las Agencias de Viajes: una visión comparada de la normativa específica en materia de turismo", en Actas del II Congreso de Turismo Universidad y Empresa, celebrado los días 21 a 23 de abril de 1999 en Benicássim, Castellón, ed. Tirant lo Blanch, Valencia, 2000.

J. A. TAMAYO ISASI ISASMENDI, "Principios informadores de la regulación administrativa hotelera", en I Congreso Italo-Español de Profesores de Derecho Administrativo, celebrado los días 17 y 18 de mayo de 1966 en Sevilla, ed. Servicio de Publicaciones del Ministerio de Información y Turismo, Madrid, 1970.

J. TUDELA ARANDA, “Aproximación al Derecho del turismo de montaña y de las estaciones de esquî", en Actas del I Congreso Universitario de Turismo, 
celebrado los días 27 a 29 de octubre de 1998 en Peñíscola, Castellón, ed. Tirant lo Blanch, Valencia, 1999.

L. URUÑUELA FERNÁNDEZ, "Comentarios a la regulación de los estudios de Técnicos de Empresa Turística”, en I Congreso Italo-Español de Profesores de Derecho Administrativo, celebrado los días 17 y 18 de mayo de 1966 en Sevilla, ed. Servicio de Publicaciones del Ministerio de Información y Turismo, Madrid, 1970.

D. J. VERA JURADO, "Actividad turística y espacios naturales protegidos", en III Jornadas de Derecho Turístico, celebradas lo días 10, 11 y12 de mayo de 2000, en Málaga, ed. Servicio de Publicaciones de la Consejería de Turismo y Deporte de la Junta de Andalucía, Sevilla, 2000.

AA.VV (Dirs. J.E. SORIANO GARCÍA y M.T. CABEZAS HERNÁNDEZ), I Congreso de Derecho Administrativo Turístico, celebrado los días 16 a 20 de octubre de 2000, Universidad de Extremadura, Cáceres, 2002.

AA. VV (Dir. D. BLANQUER CRIADO), V Congreso de Turismo Universidad y Empresa "La calidad integral del turismo", celebrado los días 23 a 25 de abril de 2002, en Benicàssim (Castellón), ed. Tirant lo Blanch, Valencia, 2003.

\section{Enciclopedias y Diccionarios.}

ACADEMIA INTERNACIONAL DE TURISMO (MONTE-CARLO), Diccionario Turístico Internacional, Monte-Carlo, traducción por José Ignacio de Arrillaga, 1970.

E. ALCARAZ VARO (dir.), Diccionario de términos de turismo y de ocio: Inglés-Español, Spanish-English, ed. Ariel, 2000.

L. ARRAZOLA (Dir.); P. SAIZ DE ANDINO; V. VALOR; J. ROMERO GINER; P. GÓMEZ DE LA SERNA, y otros, Enciclopedia española de Derecho y Administración o Nuevo Teatro Universal de la Legislación de España e Indias, XII vol., Imprenta de los Srs. Andrés y Díaz, C/ Del Amor de Dios, núm. 15, Madrid, 1849.

J. FELIPE GALLEGO, Diccionario de hosteleria: hostelería y turismo, restaurante y gastronomía, cafetería y bar, ed. Paraninfo, Madrid, 1999. 
J. JAFARI, Encyclopedia of tourism, Routledge, London-New York, 2000.

J. MONTANER MONTEJANO (dir.), Diccionario de Turismo, ed. Síntesis, Madrid, 1998.

A. XAVIER PÉREZ Y LÓPEZ, Teatro de la Legislación Universal de España é Indias, XXVIII vol., Imprenta de Manuel GONZÁLEZ, Madrid, 1791.

AA.VV, Enciclopedia Jurídica Básica, ed. Civitas, Madrid, 1995.

AA.VV, Enciclopedia Jurídica Española, Francisco Seix (editor), Barcelona, 1910 (en 1950 comenzó la publicación de la Nueva Enciclopedia Jurídica).

II. DERECHO ADMINISTRATIVO DEL TURISMO ITALO-FRANCÉS

\section{Bibliografía italiana y francesa seleccionada.}

\subsection{Italiana.}

A. ANDREANI e L. CASAGNI LIPPI, Legislazione del Turismo. Corso di Lezioni, CEDAM, Padova, 1997.

G. ARCHIMEDE e I. DEL CASTILLO, Il turismo e la sua disciplina giuridica, Terza edizione, ristampa, Zanichelli, Bologna, 1999.

T. da BALLARINO e R. PUGLIESE, Codice del turismo, Pirola editore, Milano, 1989.

F. BARTOLOMEI, "Léspropriazione per fini turistici", Rivista Trimestrale di Diritto Pubblico, 4, (1966), Giuffré editore, pp. 832-857, y en I Congreso ItaloEspañol de Profesores de Derecho Administrativo, celebrado en Sevilla los días 17 y 18 de mayo de 1966, ed. Ministerio de Información y Turismo, Madrid, 1970, pp. 219 a 230.

G. BERTOCCHI e S. FOA, Il turismo come servicio pubblico, Giuffrè editore, Milano, 1996.

R. BIN, "Interventi regionali nel turismo en el commercio", Le Regioni, Rivista di Documentazione e Giurisprudenza, Milano, 2-3, (1979), pp. 256-276. 
J. BONET CORREA, "Lórdinamiento turistico spagnolo", Bolletino Informativo dell' Istituto Giuridico Spagnolo in Roma, 48-49, Roma, (1965).

G. CANTALAMESSA CARBONI, "Problemi giuridico-sanitari dei comlessi ricettivi turistici”, Il Cornieri Amministrativo, 1-2, Empoli, (1968).

A. G. CHIZZONITI, Codice del turismo religioso, Giuffré editore, Milano, 1999.

G. CIURNELLI; S. MONTICELLI; e G. ZUDDAS, Il contratto d'albergo, il contratto di viaggio, i contratti del tempo libero, Giufré editore, Milano, 1994.

M. P. CHITI, Profilo pubblico del turismo, Giuffré editore, Milano, 1970.

M. CHITI, "Il problema degli enti pubblici nazionali operanti nelle materie regionali: il caso dell'E.N.I.T”, Le Regioni, Rivista di Documentazione e Giurisprudenza, Milano, 1, (1975), pp. 150-167.

M. CHITI, "Il problemi giuridici della política del turismo", Le Regioni, Rivista di Documentazione e Giurisprudenza, Milano, 4, (1987), pp. 585-620.

A. CIRALLI, "Le nuove norme legislative sulle aziende autonome di cura, soggiorno e turismo", Nuova Rassegna di Legislazione, Dottrina e Giurisprudenza, 5, Firenze, (1961).

S. D'AlBERGO, "Gli enti pubblici nel turismo", Rivista Trimestrale di Diritto Pubblico, 1, Milano, (1967).

E. DIAMANTI, "Il turismo", a cura di S. CASSESE, Trattato di Diritto Amministrativo. Diritto Amministrativo Speciale, T. Terzo, Giuffré editore, Milano, 2000, pp. 2773-2790.

V. DOMENICHELLI, "Il turismo nell'attivitá legislativa delle Regioni a Stato ordinario", Le Regioni, Rivista di Documentazione e Giurisprudenza, Milano, 2, (1975), pp. 294-315.

I. FABRIS, Legislazione turística, CEDAM, Padova, 1997.

U. FRAGOLA, "Appunti sul turismo come attività giuridica”, en I Congreso Italo-Español de Profesores de Derecho Administrativo, celebrado en Sevilla los días 17 y 18 de mayo de 1966, ed. Ministerio de Información y Turismo, Madrid, 1970, pp. 65 a 80. 
"La posizione del giurista dinanzi alla legislazione turística", en I Congreso Italo-Español de Profesores de Derecho Administrativo, celebrado en Sevilla los días 17 y 18 de mayo de 1966, ed. Ministerio de Información y Turismo, Madrid, 1970, pp. 83 y 84 .

"Ancora intorno al transferimento alle región delle materie turistiche (con nota di Gino Messeri)", Nuova Rassegna di Legislazione, Dottrina e Giurisprudenza, 3 y 4, Firenza, (1971).

U. FRAGOLA, Nuovi studi sul turismo, Eugenio Jovene, Napoli, 1972.

U. FRAGOLA, Códice di Legislazione del Turismo, Ipsoa editore, Milano, 1995.

V. FRANCESCHELLI e G. SILINGARDI (coordinato), Manuale del diritto del turismo, Torino, G. Giappechelli editore, Torino, 1999.

F. GAETANO e G. DE CESARE, "Gli enti provinciali del turismo", Rivista Trimestrale di Diritto Pubblico, 4, (1966), Giuffré editore, pp. 802-831.

M. S. GIANNINI e O. SEPE, "L'organizzazione Turística in Italia", Rivista Trimestrale di Diritto Pubblico, 4, (1966), Giuffré editore, pp. 763-801.

"I soggetti pubblici che operano del campo del turismo", en I Congreso Italo-Español de Profesores de Derecho Administrativo, celebrado en Sevilla los días 17 y 18 de mayo de 1966, ed. Ministerio de Información y Turismo, Madrid, 1970, pp. 19 a 28

F. GIORGETTI, La recezione del turismo nell ordinamiento internacionales e svizzero, éditions Unversitaires Fribourg Suisse, 2000.

S. HONORATO, “Turismo”, Novísimo Digesto Italiano, T. XIX, Torino, 1973.

F. INDOVINO FABRIS, Legislazione Turística, Terza edizione, CEDAM, Padova, 1992.

A. MANITTO, "La situazione attuale del turismo nel quadro delle politiche d'intervento (con nota di Gino Messeri)", Nueva Ressegna di Legislazione, Dottrina e Giurisprudenza, 3, Firenze, (1968).

A. MANITTO, "Orientamenti della politica del turismo nell'ambito della concorrenza note al programa quinquennale”, Nueva Ressegna di Legislazione, Dottrina e Giurisprudenza, 10, Firenze, (1970). 
L. MARRANGHELLO, La riforma del Turismo. Legge 29 marzo 2001, $n^{\circ}$ 135, Sal Editore, Lugano, 2001.

G. S. MELE, "I regolamenti in generale con particolari cenni in quelli ospedalieri (con nota di Eligio Gammucci)", Nueva Ressegna di Legislazione, Dottrina e Giurisprudenza, 10, Firenze, (1970).

G. MESSERI, "Prospettive per una nuova organizzazione turística (con nota di Mario Bandinelli)", Nueva Ressegna di Legislazione, Dottrina e Giurispruden$z a, 5$, Firenze, (1964).

G. MESSERI, "I mutui delle aziende autonome di cura, soggiorno e turismo", Nueva Ressegna di Legislazione, Dottrina e Giurisprudenza, 9, Firenze, (1969).

G. MESSERI, "L'esercizio delle funzioni amministrative nelle región con riferimento al settore turístico", Nueva Ressegna di Legislazione, Dottrina e Giurisprudenza,10, Firenze, (1970).

G. MESSERI, "Trasferimento delle funzioni satatali alle regioni. Turismo e industria alberghiera”, Nueva Ressegna di Legislazione, Dottrina e Giurispruden$z a$, núms. 9-10, Firenze, (1972).

A. OLIVA, "Dal territorio le nuove oportunita di sviluppo: un approcio per la definizione e la valorizzazione dei Sistemi Turistici Locali”, Ufficio Economico Confesercenti Nazionale, Roma, Aprile, (2001).

P. A. ROMANO e R. FUSCO, Codice della legislazione turística. Leggi statali e regionali, Giffré editore, Milano, 1986.

M. A. STEFANELLI, La riforma della amministrazione pubblica del turismo, CEDAM, Padova, 1995.

F. TEDESCHINI, Diritto pubblico per il turismo, Franco Angeli Libri, Milano, 1988.

G. VIGNOCCHI, "Il turismo nel nuovo ordinamiento regionale", Nueva Ressegna di Legislazione, Dottrina e Giurisprudenza, 10, Firenze, (1970).

P. VIRGA, "Turismo", en Diritto Amministrativo. Attivitá e prestazioni, Vol. IV, seconda edizione, Giuffré editore, Milano, 1994, pp. 97-109. 


\subsection{Francesa.}

C. BUREAUX et E. BUREAUX, Droit el organisation du turisme en France, édition Licet, 1988.

C.E.C.O.D., Le Tourisme en France, París, 1986.

CONSEIL NATIONAL DU TOURISME, La décentralisation et la répartion des compétences dans le domaine du tourisme, ministère du Tourisme, 1991.

C.N.A.R.L.H., Precis de Legislation sociale en restauration el Hôtelleire, París, 1984.

J. CLUZEL, Les pouvoirs publics et le thermalisme, ed. L.G.D.J., París, 1983.

M. DENEAU, P. COURTIN, Droit et droit du tourisme, Bréal editions, París, 1996.

F. FRANGIALLI, "Le tourisme dans la vie administrative et l'organisation gouvernementale de la France", Tourisprudence, 6, septembre, (1991), pp. 3-19.

G.O.T., "Les dossiers de la Gazette officielle du tourisme, 1977-1985, neuf ans dórganisation du tourisme en France”, mai 1986, n․ hors serie.

L. M., JOCARD, Le tourisme et l'action de l'Etat, ed. Berger-Levrault, l'Administration nouvelle, 1965.

M. JOPPE, L'intervention de l'Etat dans le domaine du turisme, Thèse Aix-Marseille, ed. Danisa, 1983.

JOURNAL OFFICIEL, Code du Tourisme, 3 Tom., Journal officiel, nº 1445.

J. LEONNET et P. FONTAINE, Le droit du turisme et des voyages, J. Dalmas et Cie, París, 1971.

J. M. PONTIER, "Le rôle des colllectivités locales dans la commercialisation des produits touristiques", Colloque sur la commercialisation des produits touristiques, Tourismes, Revue d'information du C.R.T., Montpellier, (1989).

F. POTRON, "Décentralisation et tourisme”, Espaces, 78, février, (1986), p. 9. 
P. PY, "L'intégration du tourisme au sein de l'administration française, in L'intervention économique de la personne publique", études en l honner du doyen G. Pequignot, Ceram, Montpellier, mai 1984.

P. PY, "La réforme de l'organisation régionale du tourisme", A.J.D.A., 6, juin, (1987), p. 386.

"La loi du 23 décembre 1992 portant répartition des compétences dans le domaine du tourisme”, R.D.P.,1, janvier-février, (1994), pp. 215-269.

"Quelle administration pour le tourisme francais?", Espaces, 129, septembreoctobre, (1994), pp. 4-6.

P. PY, Droit du tourisme, $4^{\circ}$ édition, Dalloz, París, 1996.

Y. RAYNOUARD, "Les administrations du tourisme", Espaces, 78, fevrier, (1986).

C. ROUSSEL, L'organisation du tourisme en France, éd. BPI, París, 1989.

D. RUBIO-AYACHE, Droit du tourisme, agences de voyages, Editions BPI, 1994.

F. SERVOIN, Institutions touristiques et droit du tourisme, Masson, París, 1981.

F. SERVOIN, "L'organisation locale du tourisme en France", Tourisprudence, 3, décembre, (1990), pp. 3-32. 